\title{
Gioia Paradisi, Le passioni della storia. Scrittura e memoria nell'opera di Wace
}

\section{Walter Meliga}

\section{(2) OpenEdition}

1 Journals

\section{Edizione digitale}

URL: http://journals.openedition.org/studifrancesi/27241

DOI: 10.4000/studifrancesi.27241

ISSN: 2421-5856

\section{Editore}

Rosenberg \& Sellier

\section{Edizione cartacea}

Data di pubblicazione: 31 décembre 2006

Paginazione: 577

ISSN: 0039-2944

\section{Notizia bibliografica digitale}

Walter Meliga, "Gioia Paradisi, Le passioni della storia. Scrittura e memoria nell'opera di Wace », Studi

Francesi [Online], 150 (L | III) | 2006, online dal 30 novembre 2015, consultato il 08 novembre 2020. URL : http://journals.openedition.org/studifrancesi/27241 ; DOI : https://doi.org/10.4000/ studifrancesi.27241

\section{Questo documento è stato generato automaticamente il 8 novembre 2020.}

\section{(c) (1)}

Studi Francesi è distribuita con Licenza Creative Commons Attribuzione - Non commerciale - Non opere derivate 4.0 Internazionale. 


\title{
Gioia Paradisi, Le passioni della storia. Scrittura e memoria nell'opera di Wace
}

\author{
Walter Meliga
}

\section{NOTIZIA}

GIOIA PARADISI, Le passioni della storia. Scrittura e memoria nell'opera di Wace, Roma, Bagatto Libri («Dipartimento di studi romanzi, Università di Roma "La Sapienza”. Testi, studi e manuali», 16), 2002, pp. 458.

1 Il libro di Gioia Paradisi è un lavoro di ampio respiro sulla figura di Wace, importante autore normanno della metà del sec. XII nei generi dell'agiografia e soprattutto della storiografia, dove si contano due romanzi (il Roman de Brut, volgarizzamento dell' Historia regum Britanniae di Goffredo di Monmouth, e il Roman de Rou, racconto delle imprese dei duchi di Normandia) di grande rilievo nel panorama della nuova letteratura volgare. Paradisi studia con grande attenzione la produzione e l'autore: in particolare, l'indagine sulla figura di intellettuale di Wace e sui suoi rapporti con la corte plantageneta insieme a quella sui modelli ai quali egli si è ispirato per i due romanzi (Goffredo di Monmouth e le sue fonti insulari, la storiografia normanna in latino) fanno di questo lavoro un riferimento assolutamente imprescindibile. 